\title{
Comparison of the bronchial response to running and cycling in asthma using an improved definition of the response to work
}

\author{
G.J . M I L L E R 1, B. H. D A V I E S , T. J . C O L E, \\ a n d A. S E A T O N \\ Medical Research Council Pneumoconiosis Unit, Penarth, and Sully Hospital, Sully, Glamorgan, S. Wales
}

\begin{abstract}
Miller, G. J., Davies, B. H., Cole, T. J., and Seaton, A. (1975). Thorax, 30, 306-311. Comparison of the bronchial response to running and cycling in asthma using an improved definition of the response to work. The bronchial responses to treadmill running and ergometer cycling have been compared in 13 adults with asthma. The exercises were performed on separate days with an interval ranging from three days to six months. The study was designed to ensure that the time course of oxygen consumption during running was replicated during cycling. The response to exercise was estimated by taking serial measurements of the maximum forced expiratory flow rate and forced expiratory volume in one second before and after work. Indices used to describe the response were $(b-a) / b$ and $a / b$, where $b$ and $a$ were the average lung function before and the lowest value after exercise respectively.

There was no significant difference in the lung function of the subjects before running and cycling nor did the duration of exercise or oxygen consumption differ between the two exercises. Eleven of the 13 patients showed a reduction in ventilatory capacity after both forms of exercise. Differences in the lung function responses to the two forms of standard work were trivial and not statistically significant, amounting to only about $1 \%$. It is suggested that previous reports of larger responses to running than cycling were probably due to higher energy expenditures during running. General problems regarding the description and comparison of the responses to exercise are discussed.
\end{abstract}

The systematic study of exercise-induced asthma followed from its description by Pearson in 1952. The airways obstruction induced has been reported to vary with the intensity, duration (Silverman and Anderson, 1972), and type of work performed. Anderson, Connolly, and Godfrey (1971) and Anderson, Silverman, and Walker (1972) considered running to be more effective than cycling in this respect and speculated on the nature of this difference (Silverman, Anderson, and Walker, 1972).

When repeated measurements are made on two or more occasions on the same subject in order to describe and compare the responses to different types of exercise, care must be taken to standardize energy expenditure and to use indices which describe the responses appropriately. These problems are illustrated and discussed using the results of a study which compared the bronchial responses to running and cycling in 13 adults with asthma.

${ }^{1}$ Present address: MRC Epidemiology Unit, University of the West Indies, Kingston 7, Jamaica

\section{PATIENTS AND METHODS}

Six men and seven women (mean age 28 , range 19-44 years) gave informed consent to the study All were attending the Cardiff Asthma Clinic. Fous had developed asthma within the four years before the present study, and the remainder had experiencedP their first attack in childhood. Eleven had immediat (reaginic) cutaneous responses to several commonallergens, and both they and the other two, who dids not show skin sensitivity, had widely variable airways obstruction responsive to salbutamol. All save two心 in common with the majority of asthmatics, gave $\alpha^{\omega}$ history that attacks of wheeze could be provokeck by exertion, though this was not used as a criterior for selection of the patients for this study. No patien was receiving either corticosteroids or disodium cromoglycate, and no drugs at all were taken on the test days until all measurements had been completed $\vec{\Phi}$

The same measurements were made in an identicaf manner on each patient on two occasions separated $\mathbb{P}^{2}$ by an interval which ranged from three days to six months. Treadmill running and ergometer cycling 
were performed on the first and second test days respectively, and the study was designed to ensure that both the duration of exercise and total oxygen consumption during work were very similar on the two occasions. On the five days preceding each test exercise subjects entered on a diary card the best of three measurements of the forced expiratory peak flow rate (measured with a Wright peak flow meter) three times daily. In addition, total lung capacity and its subdivisions (helium dilution) and the average of two estimates of the carbon monoxide transfer factor (single-breath method) were recorded with a Resparameter shortly before each test exercise. These measurements were made to ensure that each patient had been in a similar state of respiratory health at the times when test exercise was performed.

The response to exercise was followed by having the patient make two forced expirations into a low resistance dry spirometer (Ohio 840 coupled to an oscilloscope and an ultraviolet chart recorder) at 5 minutes and immediately before work and at 5minute intervals after work until 20 minutes. The maximum flow rate and volume expired in one second $\left(\mathrm{FEV}_{1}\right)$ were estimated for each recorded breath, and volumes were expressed in litres at body temperature and pressure saturated with water (litres BTPS). For each index the average of the four measurements before exercise was considered the best estimate of resting lung function. The lowest average value for the pairs of estimates made after exercise was taken to be the maximum response to work. Average normal values for maximum flow were taken from Leiner et al. (1963) and for other lung function indices from Cotes (1968).

The first test exercise consisted of running on a horizontal treadmill at about $100 \mathrm{~m} \mathrm{~min}^{-1}$, depending on body size, until either approximately $0.45 \mathrm{~mol}$ (10 litres STPD) of oxygen had been consumed or the patient wished to stop, whichever was the sooner. Each walked on the treadmill at about $40 \mathrm{~m} \mathrm{~min}^{-1}$ for one minute before commencing the run. The patient breathed through a low resistance, low deadspace respiratory valve (Bannister and Cormack, 1954) and mouthpiece. Inspired air was drawn through a dry-gas meter (Parkinson and Cowan, CD4) which was coupled to an electronic ventilation meter. This provided digital displays of the accumulating ventilation volume in each minute and the total ventilation during the previous minute. Expired air was returned to atmosphere through a gas-mixing chamber (capacity 4.51 .) from which a sample was continuously drawn and passed in turn through a drying-tube, paramagnetic oxygen meter (Servomex OA 150) and an infrared carbon dioxide meter (Irga, Grubb-Parsons). Oxygen consumption for each minute or part of a minute and the accumulated oxygen consumption at any time during exercise were monitored as work progressed by entering ventilation volume and expired gas concentrations directly into a suitably programmed desk calculator.

Patients were studied on the second occasion provided their lung function was close to that on the first test day. A graph was plotted of the time course of oxygen consumption during treadmill exercise, and the aim during the second test was to replicate this time course during ergometer cycling. In order to achieve this the appropriate initial ergometer setting was estimated in watts (W) taking the energy equivalent of oxygen to be $448 \mathrm{~J} \mathrm{mmol}^{-1}$ (Royal Society, 1972) and the average efficiency of ergometer cycling to be $24 \%$ at $100 \mathrm{~W}$ steady-state (Nowacki, 1968). Since watts equal joules per second the calculation reduced to: Initial ergometer setting $(W)=$ required average oxygen uptake $\left(\mathrm{mmol} \mathrm{min}^{-1}\right) \times 1 \cdot 8$.

Cycling exercise was performed on an electromagnetically braked ergometer (Lanooy). This provided flexible control of the power output and automatic adjustment of the resistance to pedalling so that, within limits, power output was independent of pedalling frequency. Patients cycled for one minute on the unbraked ergometer before starting the test exercise. Fine adjustments were made to the brake setting when necessary as the exercise proceeded, and the test was terminated when the target total oxygen consumption had been achieved. Patients were encouraged to tolerate any leg pain or fatigue induced by the cycling.

The response to exercise was initially described in the conventional form as the fractional decrease in lung function, $(b-a) / b$ (Jones, Buston, and Wharton, 1962), where $b$ was the estimate before exercise and $a$ the lowest value after exercise, and the significance of differences in response to running and cycling was examined with a paired sample $t$ test. Subsequently, for reasons discussed later, the response was described as $a / b$, and (because this was a proportionality) the paired sample $t$ test was performed on its logarithmic form, $\log _{e}(a / b)$. Differences were considered significant if the probability of occurrence by chance alone was less than $5 \%$.

\section{RESULTS}

Table I presents the average peak flow rate, lung volumes, and transfer factor for the group before running, together with the average change when remeasured before cycling. Lung function was very similar on the two occasions.

Table II shows that the duration of work, total oxygen consumption, and average rate of oxygen consumption were very similar during running and 
T A B L E I

COMPARISON OF LUNG FUNCTION BEFORE RUNNING AND CYCLING

\begin{tabular}{|c|c|c|c|c|}
\hline \multirow[b]{2}{*}{ Index } & & \multirow{2}{*}{$\frac{\text { Running }}{\text { Mean }}$} & \multicolumn{2}{|c|}{ Running-Cycling } \\
\hline & & & Mean & $\pm \mathrm{SE}^{2}$ \\
\hline $\begin{array}{l}\text { Average peak expiratory flow rate over five days }{ }^{1} \\
\text { Total lung capacity } \\
\text { Functional residual capacity } \\
\text { Residual volume } \\
\text { Transfer factor }\end{array}$ & $\begin{array}{l}1 \min ^{-1} \\
\text { 1. } \\
\text { I. } \\
\text { i. } \\
\text { mol } \min ^{-1} \mathbf{k P a}^{-1}\end{array}$ & $\begin{array}{l}373(69) \\
6.06(98) \\
3 \cdot 38(110) \\
1 \cdot 75(100) \\
10.9(104)\end{array}$ & $\begin{array}{l}+1 \\
-0.18 \\
-0.02 \\
+0.02 \\
+0.4\end{array}$ & $\begin{array}{l}11 \cdot 4 \\
0 \cdot 19 \\
0 \cdot 12 \\
0 \cdot 11 \\
0 \cdot 3\end{array}$ \\
\hline
\end{tabular}

Figures in parentheses are means expressed as a percentage of predicted average normal for the group (Leiner $e$ t al., 1963; Cotes, 1968). 'Eleven patients only.

'Paired $t$ test: none of the differences was statistically significant.

T A B L E I I

COMPARISON OF EXERCISE PERFORMANCE DURING RUNNING AND CYCLING

\begin{tabular}{|c|c|c|c|c|c|}
\hline \multirow[b]{2}{*}{ Index } & & \multirow{2}{*}{$\frac{\text { Running }}{\text { Mean }}$} & \multicolumn{3}{|c|}{ Running-Cycling } \\
\hline & & & Mean & $\pm \mathbf{S E}$ & $\mathrm{P}^{2}$ \\
\hline $\begin{array}{l}\text { Duration of exercise } \\
\text { Total oxygen consumption }{ }^{1} \\
\text { Rate of oxygen consumption }{ }^{1} \\
\text { Total ventilation }\end{array}$ & $\begin{array}{l}\text { seconds } \\
\text { mmol } \\
\text { mmol min-1 } \\
\text { l. BTPS }\end{array}$ & $\begin{array}{l}341 \\
391 \cdot 1 \\
67 \cdot 9 \\
250 \cdot 1\end{array}$ & $\begin{array}{r}-6 \\
+1.8 \\
+0.4 \\
-18.8\end{array}$ & $\begin{array}{l}8 \\
4.0 \\
1.9 \\
6.9\end{array}$ & $\begin{array}{l}\text { NS } \\
\text { NS } \\
\text { NS } \\
<0.02\end{array}$ \\
\hline
\end{tabular}

${ }^{2}$ Paired $t$ test.

NS $=$ not significant.

T A B L E I I I

INDIVIDUAL RESULTS OF FORCED EXPIRATORY MAXIMUM FLOW RATE (MEFR) AND FORCED EXPIRATORY VOLUME IN ONE SECOND (FEV $)_{1}$ BEFORE (b) AND AFTER (a) EXERCISE

\begin{tabular}{|c|c|c|c|c|c|c|c|c|c|c|}
\hline \multirow{3}{*}{ Patient } & \multirow{3}{*}{ Sex } & \multirow{3}{*}{ Age (years) } & \multicolumn{4}{|c|}{$\operatorname{MEFR}\left(1 \min ^{-1}\right)$} & \multicolumn{4}{|c|}{$\mathrm{FEV}_{1}$ (litres) } \\
\hline & & & \multicolumn{2}{|c|}{ Treadmill } & \multicolumn{2}{|c|}{ Cycle } & \multicolumn{2}{|c|}{ Treadmill } & \multicolumn{2}{|c|}{ Cycle } \\
\hline & & & $b^{1}$ & $a^{2}$ & $b^{1}$ & $\mathrm{a}^{2}$ & $b^{1}$ & $a^{2}$ & $b^{1}$ & $a^{2}$ \\
\hline $\begin{array}{r}1 \\
2 \\
3 \\
4 \\
5 \\
6 \\
7 \\
8 \\
9 \\
10 \\
11 \\
12 \\
13\end{array}$ & $\begin{array}{l}\mathbf{M} \\
\mathbf{M} \\
\mathbf{M} \\
\mathbf{F} \\
\mathbf{F} \\
\mathbf{F} \\
\mathbf{F} \\
\mathbf{F} \\
\mathbf{M} \\
\mathbf{F} \\
\mathbf{F} \\
\mathbf{M} \\
\mathbf{M}\end{array}$ & $\begin{array}{l}19 \\
24 \\
25 \\
21 \\
35 \\
36 \\
26 \\
24 \\
43 \\
21 \\
24 \\
24 \\
44\end{array}$ & $\begin{array}{l}410 \\
314 \\
626 \\
437 \\
403 \\
408 \\
288 \\
437 \\
480 \\
420 \\
444 \\
504 \\
728\end{array}$ & $\begin{array}{l}233 \\
300 \\
617 \\
360 \\
140 \\
264 \\
180 \\
380 \\
420 \\
277 \\
420 \\
392 \\
690\end{array}$ & $\begin{array}{l}304 \\
443 \\
626 \\
409 \\
330 \\
417 \\
218 \\
439 \\
493 \\
379 \\
387 \\
446 \\
687\end{array}$ & $\begin{array}{r}225 \\
387 \\
626 \\
338 \\
62 \\
375 \\
188 \\
332 \\
399 \\
277 \\
262 \\
385 \\
667\end{array}$ & $\begin{array}{l}2 \cdot 56 \\
2 \cdot 59 \\
6.00 \\
2 \cdot 86 \\
3.08 \\
2 \cdot 89 \\
1 \cdot 83 \\
3.30 \\
3 \cdot 35 \\
2 \cdot 18 \\
2.44 \\
2 \cdot 78 \\
4 \cdot 83\end{array}$ & $\begin{array}{l}1.61 \\
2.29 \\
5.83 \\
1.89 \\
2.58 \\
1.78 \\
1.33 \\
3.41 \\
3.24 \\
1.76 \\
2.25 \\
2.17 \\
4.78\end{array}$ & $\begin{array}{l}1 \cdot 89 \\
3 \cdot 14 \\
5.07 \\
2.62 \\
2.90 \\
2.89 \\
1.82 \\
3.30 \\
3.03 \\
2.51 \\
2.19 \\
2.50 \\
3.36\end{array}$ & $\begin{array}{l}1.61 \\
2.17 \\
4.94 \\
1.83 \\
2.43 \\
2.44 \\
1.50 \\
2.56 \\
2.69 \\
2.08 \\
1.48 \\
2.44 \\
3.44\end{array}$ \\
\hline
\end{tabular}

${ }_{1}$ Average of four estimates.

${ }^{2}$ Lowest average value for pairs of estimates made at 5-minute intervals after exercise.

T A B L E I V

COMPARISON OF LUNG FUNCTION RESPONSES TO RUNNING AND CYCLING

\begin{tabular}{|c|c|c|c|}
\hline \multirow[b]{2}{*}{ Index } & \multicolumn{2}{|c|}{ Arithmetic Means } & \multirow{2}{*}{$\frac{\text { Running-Cycling }}{\text { Mean }( \pm S E)^{1}}$} \\
\hline & Running & Cycling & \\
\hline $\begin{array}{l}\text { Forced expiratory maximum flow rate }\left(1 \mathrm{~min}^{-1}\right) \\
\text { Before exercise }(b) \\
\text { After exercise }(a) \\
(b-a) / b \\
\log _{e} a / b\end{array}$ & $\begin{array}{l}454 \\
359 \\
0 \cdot 229 \\
-0 \cdot 295\end{array}$ & $\begin{array}{l}429 \\
348 \\
0 \cdot 216 \\
-0 \cdot 302\end{array}$ & $\begin{array}{l}+25 \quad( \pm 16) \\
+12 \quad( \pm 18) \\
+0.013( \pm 0.042) \\
+0.007( \pm 0.073)\end{array}$ \\
\hline $\begin{array}{l}\text { Forced expiratory volume in one second (1.) } \\
\text { Before exercise }(b) \\
\text { After exercise }(a) \\
(b-a) ! b \\
\text { Loge } a / b\end{array}$ & $\begin{array}{l}3 \cdot 13 \\
2 \cdot 70 \\
0 \cdot 168 \\
-0 \cdot 199\end{array}$ & $\begin{array}{l}2.86 \\
2.43 \\
0.162 \\
-0.186\end{array}$ & $\begin{array}{l}+0.27( \pm 0.16) \\
+0.26( \pm 0.17) \\
+0.005( \pm 0.049) \\
+0.013( \pm 0.062)\end{array}$ \\
\hline
\end{tabular}

'Paired sample $t$ test; none of the differences between running and cycling was statistically significant. 
cycling. The ventilation rate was about $8 \%$ greater during cycling than during running.

Individual results of ventilatory function before and after running and cycling are presented in Table III. When the response to exercise was measured as $(b-a) / b$ the mean changes in forced expiratory maximum flow rate after running and cycling were respectively $-23 \%$ (range $-1.4 \%$ to $-65.3 \%$ ) and $-22 \%$ (range $0 \%$ to $81.2 \%$ ). Mean changes in FEV $_{1}$ were $-16.8 \%$ (range $+3.3 \%$ to $-38.4 \%$ ) after running and $-16.2 \%$ (range $+2.4 \%$ to $-32.4 \%$ ) after cycling. On average, differences in the lung function response to the two exercises were trivial and not statistically significant when measured either as $(b-a) / b$ or $a / b$ (Table IV), and amounted only to about $1 \%$.

\section{DISCUSSION}

The bronchial response to standard work appeared to be reproducible in those patients with asthma included in this study irrespective of whether work was performed running or cycling. In addition, the bronchial response did not appear to be related to the ventilation rate which was greater during cycling than during running.

CONTROL OF WORK The most appropriate expression of work performance in studies of this type is in terms of oxygen consumption. Other less direct methods have been used, such as the setting on an ergometer (Fisher et al., 1970) or the exercise cardiac frequency (Fitch and Morton, 1971), but are less satisfactory. At any ergometer setting energy expenditure varies with such factors as body weight and the way work is performed (Cotes, 1972). Cardiac frequency for standard energy expenditure also varies considerably with body size (Cotes et al., 1973) and the way work is performed (Bevegard and Shepherd, 1967), together with other factors such as temperature, emotion, and drugs, including nicotine.

The form of exercise usually recommended as a test in asthma involves 6 to 8 minutes of continuous work at a constant power output which represents not less than $50 \%$ of the patient's exercise capacity (Godfrey, Silverman, and Anderson, 1973). For part and perhaps all of this time the rate of oxygen consumption will be increasing steadily. Estimates of oxygen consumption during only a part of the exercise cannot therefore describe the patient's total work performance. Furthermore, the operator cannot regulate work performance adequately unless oxygen consumption is calculated during the test procedure and not postponed until some time after work has been completed. For example, Anderson et al. (1971) measured oxygen consumption only during the last minute of exercise and even so found this to be on average $11 \%$ greater during treadmill than cycle ergometer work. Thus the finding of these workers, and also that of Anderson et al. (1972), of more bronchoconstriction after running than cycling was probably accounted for by differences in total energy expenditure during the two exercises. The methods used in the present study were designed to avoid these problems.

A disadvantage of cycling compared with running is that it involves a smaller working muscle mass. Consequently, leg fatigue is more likely to occur during cycling, as in this study. Greater motivation and tolerance of discomfort is therefore required of the patient during ergometer cycling than during running. Jones, Wharton, and Buston (1963) and Fitch and Morton (1971) also noted this problem and in consequence considered cycling to be less reliable than running in inducing bronchoconstriction.

Beaudry, Wise, and Seely (1967) found no difference in forced expiratory volume before and immediately after ergometer cycling at an average rate of oxygen consumption of $27 \mathrm{mmol} \mathrm{min}-1\left(0.61 \mathrm{~min}^{-1}\right)$. However, this was a very modest work rate even for children, and any post-exercise bronchoconstriction was very likely to have been missed since the maximum response is known not to occur until between 2 and 10 minutes after work (Katz et al., 1971; Godfrey et al., 1973). Thus this study, which in any case was designed primarily to examine gas exchange during work in normal and asthmatic children, is of little relevance to the present discussion. Fisher et al. (1970), in a study of the contributions made to exercise-induced asthma by hypocapnia and cholinergic mechanisms, commented on the greater degree of bronchoconstriction induced by stairway exercise than by cycling. However, their patients exercised on the stairs and cycle ergometer for 8 and 6 minutes respectively. In addition, the authors stated that the work rate during stairway exercise was likely to have been underestimated. In this study therefore, the relatively poor bronchial response to cycling was probably related to the lower total energy expenditure demanded by this exercise.

DESCRIPTION OF THE RESPONSE TO WORK Conventionally the response to exercise has been presented in terms of the maximum possible, that is, as $(b-a) / b$, using the arithmetic mean for grouped data (Jones et al., 1962). However, this reduces to $1-a / b$ in which only the second term contains information about the patient. Thus the response to exercise can be described equally well and more simply as $a / b$. This form emphasizes that the response is a proportion, so that grouped data should be described in terms of the geometric mean. 
The description of the response to exercise as $a / b$ is preferable to $(b-a)$ since the former relates the size of the change to the patient's average lung function which varies with body size and age. However, it may not be entirely satisfactory in asthma as the bronchi are responsive to many factors other than exercise, which makes $b$ potentially as variable as $a$. The problem is to decide the extent to which these other factors modify the patient's response to exercise.

The effect of these other factors on the bronchi can be described in terms of $b$ expressed as a proportion of lung function in health. The latter is difficult to define and is perhaps best expressed as the average expected value for subjects of similar age and body size in the general community, call it $p$. The effect of other factors is then described by $b / p$. If these other factors have no effect on the response to standard exercise they can be ignored and the most appropriate description of the effect of exercise remains $a / b$. In other words, we give full weight to the effect of exercise, $a / b$, and zero weight to the effect of other factors $b / p\left([a / b]^{1} \times[b / p]^{0}=a / b\right)$. By contrast, if these other factors are equally important in determining the response to exercise as exercise itself, we give equal weight to both terms, in which case the best description of the response is $a / p\left([a / b]^{1} \times[b / p]^{1}=a / p\right)$. Obviously there is a complete range of possibilities between the extremes so that the problem becomes a search for the most appropriate value between 0 and 1 for the weight $w$ in the expression $a /\left(b^{1-w} \cdot p^{w}\right)$ ( $w=0$ gives $a / b$ and $w=1$ gives $a / p$ ). No study has yet been designed to explore this problem. In the present investigation and also in those of Anderson et al. (1971) and Anderson et al. (1972) the group average pre-exercise lung function measurements for the patients were similar on both test days. Nevertheless there was variation in $b$ for individuals on the two test days.

The most appropriate value for $w$ can be estimated by linear regression analysis. When exercise is repeated on two occasions:

$$
a_{1} /\left(b_{1}{ }^{1-w} \cdot p_{1}{ }^{w}\right) \propto a_{2} /\left(b_{2}{ }^{1-w} \cdot p_{2}{ }^{w}\right)
$$

therefore; since $p_{1}=p_{2}$,

or:

$$
a_{1} / a_{2} \propto b_{1}{ }^{1-w} / b_{2}{ }^{1-w},
$$

Taking logarithms we have:

$$
a_{1} / a_{2}=C .\left(b_{1} / b_{2}\right)^{1-w}
$$

$$
\log _{e}\left(a_{1} / a_{2}\right)=(1-w) \log _{e}\left(b_{1} / b_{2}\right)+\log _{e} \mathrm{C} .
$$

This is in the form of a linear regression $y=a x+b$ in which $1-w$ is the regression coefficient of $\log _{e}\left(a_{1} / a_{2}\right)$ on $\log _{e}\left(b_{1} / b_{2}\right)$. Analysing our own data in this way gave $w=0.18(S E \pm 0 \cdot 48)$. Pooling our data with those for 15 patients studied by Anderson and colleagues $(1971 ; 1972)$ gave a similar result, $w=0.003$ $(\mathrm{SE} \pm \mathbf{0} \cdot 26)$. Thus in these studies $w$ was close to zero, and the most appropriate description of the response $\stackrel{\overrightarrow{5}}{+}$ to exercise was $a / b$. This will not necessarily be the? case in studies where the patient's respiratory health, and therefore $b$, differs appreciably before standard $\frac{\widehat{\rho}}{\sigma}$ exercise on the two separate occasions.

This study was not concerned with mechanisms in exercise-induced asthma. Any hypothesis as to its $\overrightarrow{0}$ cause must take account of the reproducibility of the response irrespective of whether standard work is $\vec{\omega}$ performed by running or cycling. In addition, it must $\stackrel{\circ}{=}$ account for the association between the strength of the response and (within limits) the amount of work performed (Silverman and Anderson, 1972). Whetheriw the magnitude of the response to standard work is related to the state of respiratory health at the starto of work cannot be answered at present.

We are grateful to those patients who kindly agreed to collaborate in this study. We also acknowledge ourd gratitude for technical assistance given by Ms. S. Radcliffe, $\overrightarrow{0}$ Ms. A. Sanders, Ms. E. Sanderson, Mr. M. J. Saunders, and Mr. P. J. James.

\section{REFERENCES}

Anderson, S. D., Connolly, N. M., and Godfrey, S. ֶి (1971). Comparison of bronchoconstriction inducedळ by cycling and running. Thorax, 26, 396.

—, Silverman, M., and Walker, S. R. (1972). Metabolic흘 and ventilatory changes in asthmatic patients during 9 and after exercise. Thorax, 27, 718.

Bannister, R. G. and Cormack, R. S. (1954). Two low? resistance, low dead space respiratory valves. Jour nal of Physiology, 124, 4P.

Beaudry, P. H., Wise, M. B., and Seely, J. E. (1967) Respiratory gas exchange at rest and during exercise in normal and asthmatic children. American Review3 of Respiratory Disease, 95, 248.

Bevegard, B. S. and Shepherd, J. T. (1967). Regulation of the circulation during exercise in man. Physiological Reviews, 47, 178.

Cotes, J. E. (1968). Lung Function: Assessment and Application in Medicine, 2nd edition. Blackwell, Oxford.

(1972). Response to progressive exercise: a three-बึ index test. British Journal of Diseases of the Chest, 66, N 169.

—, Berry, G., Burkinshaw, L., Davies, C. T. M., Hall A. M., Jones, P. R. M., and Knibbs, A. V. (1973) Cardiac frequency during submaximal exercise ino young adults; relation to lean body mass, total body potassium and amount of leg muscle. Quarterlyes Journal of Experimental Physiology, 58, 239.

Fisher, H. K., Holton, P., Buxton, R. St. J., and Nadel $\frac{0}{\sigma}$ J. A. (1970). Resistance to breathing during exercise $\frac{\mathbb{D}}{D}$ induced asthma attacks. American Review of Res $\Omega$ piratory Disease, 101, 885.

Fitch, K. D. and Morton, A. R. (1971). Specificity ofo exercise in exercise-induced asthma. British Medicat Journal, 4, 577. 
Godfrey, S., Silverman, M., and Anderson, S. D. (1973). Problems of interpreting exercise-induced asthma. Journal of Allergy and Clinical Immunology, 52, 199.

Jones, R. S., Buston, M. H., and Wharton, M. J. (1962). The effect of exercise on ventilatory function in the child with asthma. British Journal of Diseases of the Chest, 56, 78 .

—- Wharton, M. J., and Buston, M. H.(1963). The place of physical exercise and bronchodilator drugs in the assessment of the asthmatic child. Archives of Disease in Childhood, 38, 539.

Katz, R. M., Whipp, B. J., Heimlich, E. M., and Wasserman, K. (1971). Exercise-induced bronchospasm, ventilation, and blood gases in asthmatic children. Journal of Allergy, 47, 148.

Leiner, G. C., Abramowitz, S., Small, M. J., Stenby, V. B., and Lewis, W. A. (1963). Expiratory peak flow rate. Standard values for normal subjects. American Review of Respiratory Disease, 88, 644.

Nowacki, P. E. (1968). Der Wirkungsgrad bei ergometrischer Leistung. In: 2. Internationales Seminar für Ergometrie in Berlin, 1967, p. 241. Ergon Verlag, Berlin.

Pearson, R. B. (1952). The effect of exercise in asthmaIn: Proceedings of the British Association of Allergists Acta Allergologica, 5, 310.

Royal Society (1972). Report of the Sub-committee on Metrication of the British National Committee for Nutritional Sciences. Metric Units, Conversion Factors and Nomenclature in Nutritional and Food Sciences. The Royal Society, London.

Silverman, M. and Anderson, S. D. (1972). Standardization of exercise tests in asthmatic children. Archives of Disease in Childhood, 47, 882.

_- _ _ and Walker, S. R. (1972). The metabolic changes preceding exercise-induced bronchoconstriction. British Medical Journal, 1, 207.

Requests for reprints to: Dr. A. Seaton, Asthma Research Unit, Sully Hospital, Penarth, Glamorgan. 